\title{
BATS OF FLORIDA
}

Brazilian free-tailed bat

Tadarida brasiliensis
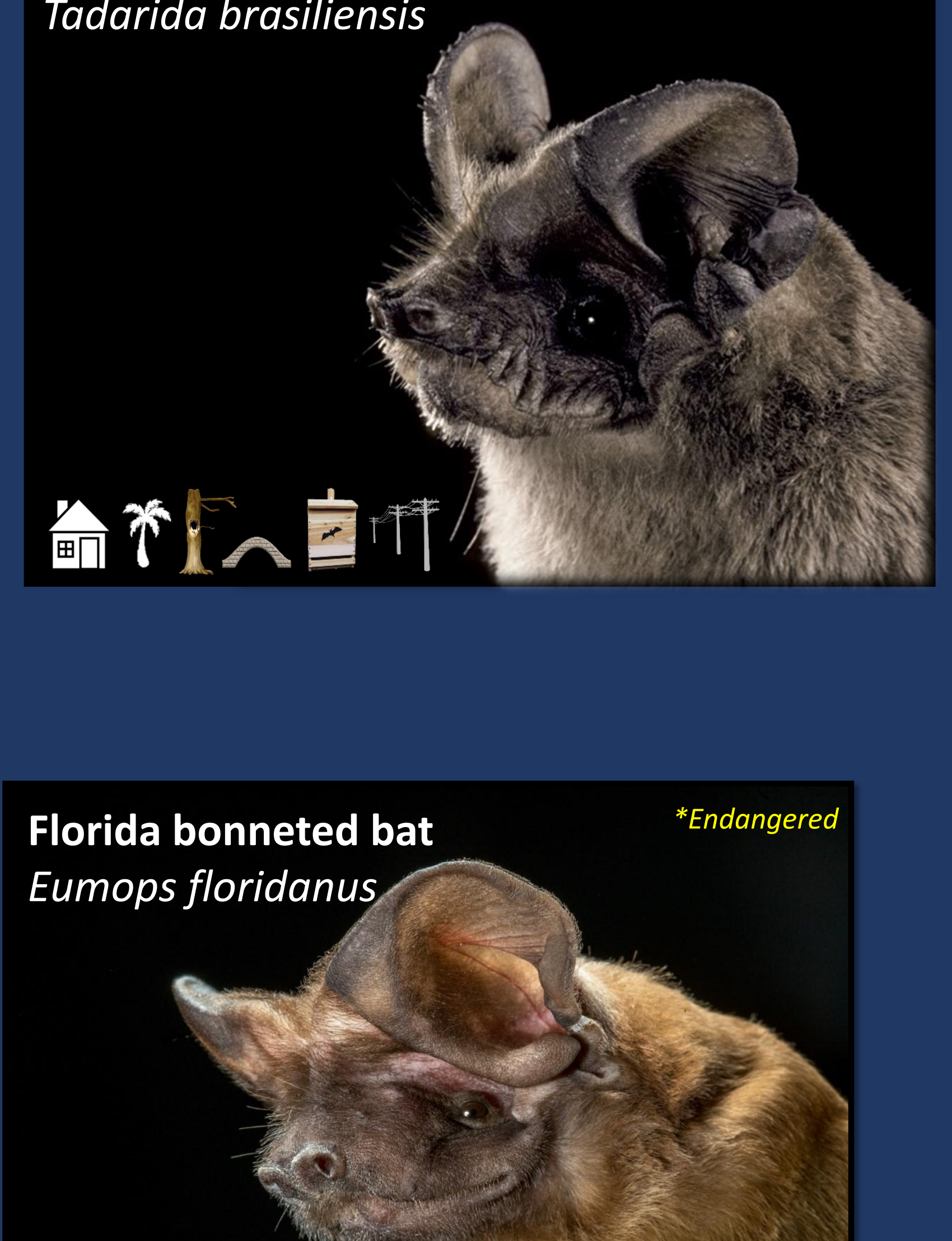

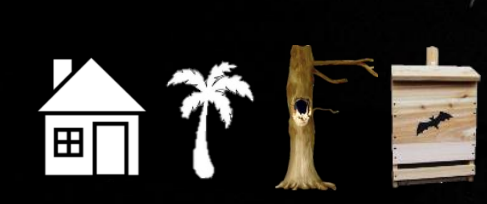
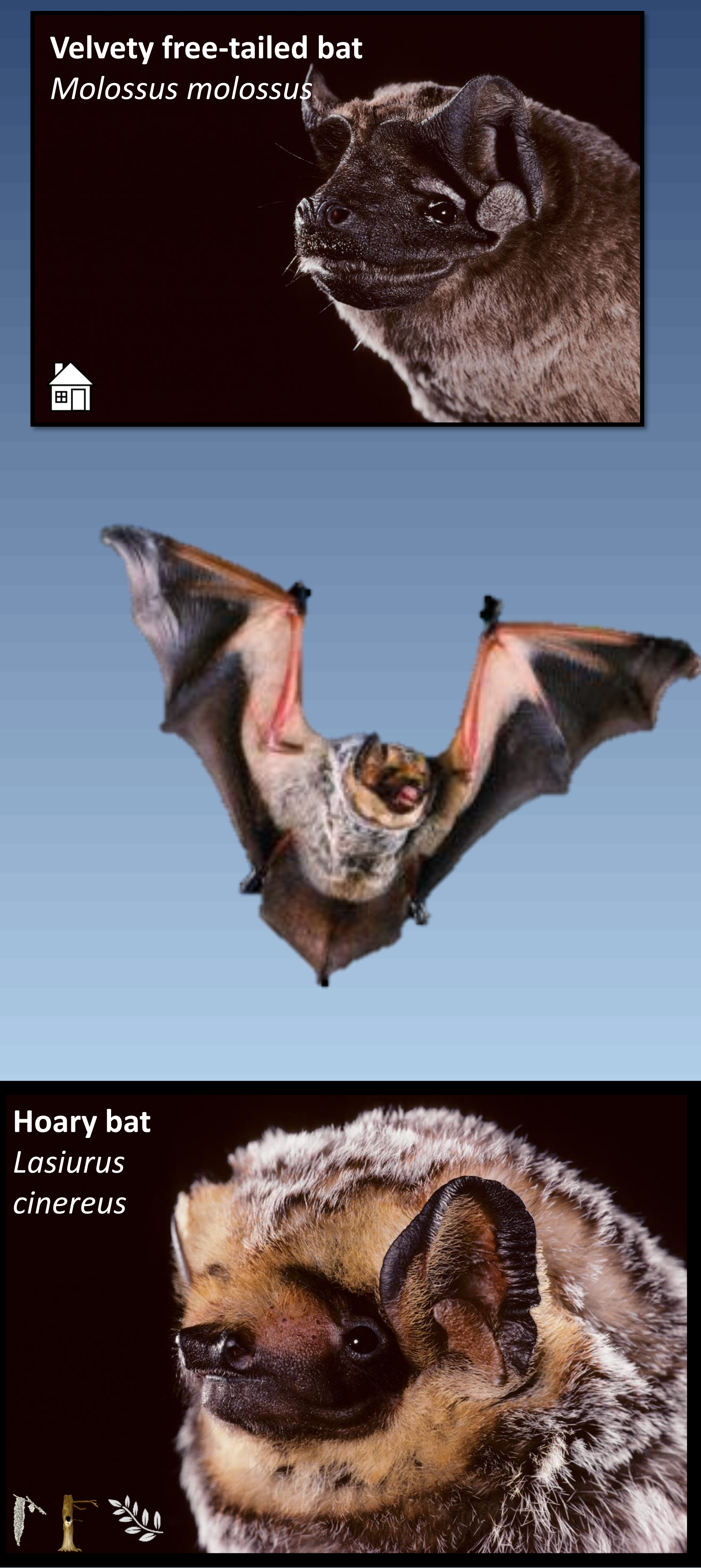

* The 13 species shown on this poster live in Florida year round There are 7 other species that are periodically observed in the Florida Keys or near the border of neighboring states to the north (Georgia or Alabama).

Created by Meghan E. Lauer and Holly K. Ober UF IFAS Extension UNIVERSITY of FLORIDA
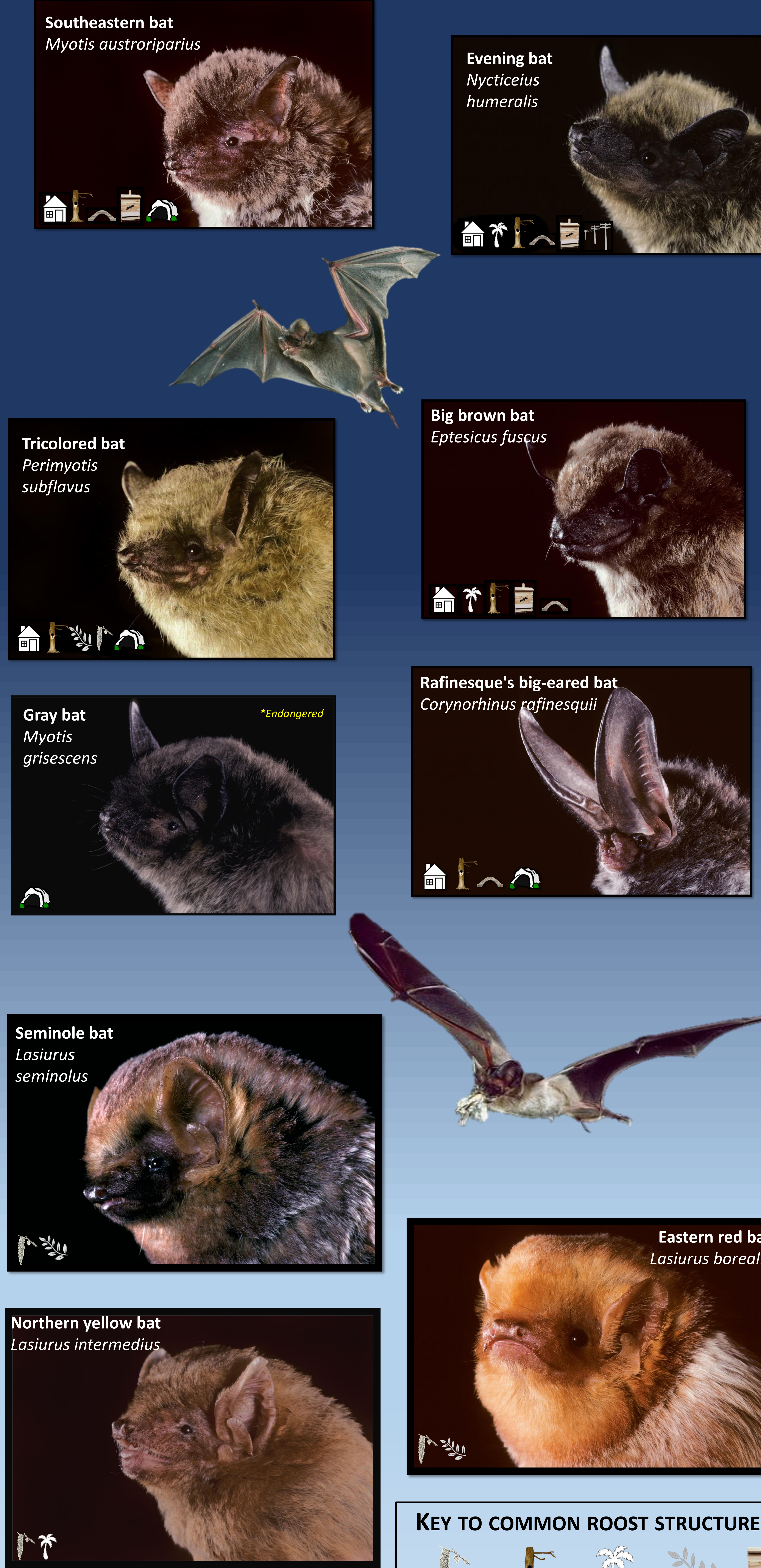

ALL PHOTOS USED WITH PERMISSION FROM CMERLINTUTtLE.ORG

Original publicaC412

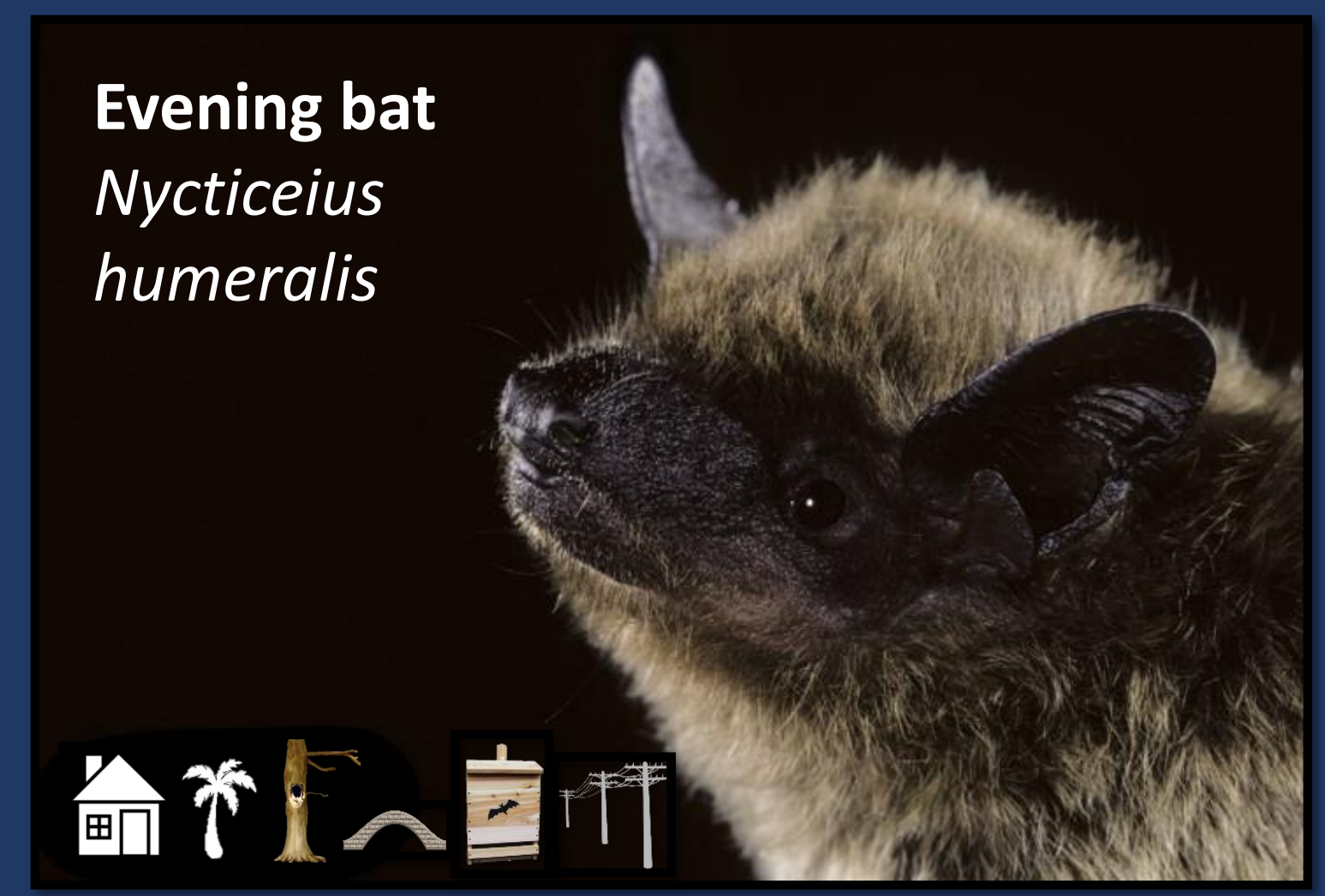

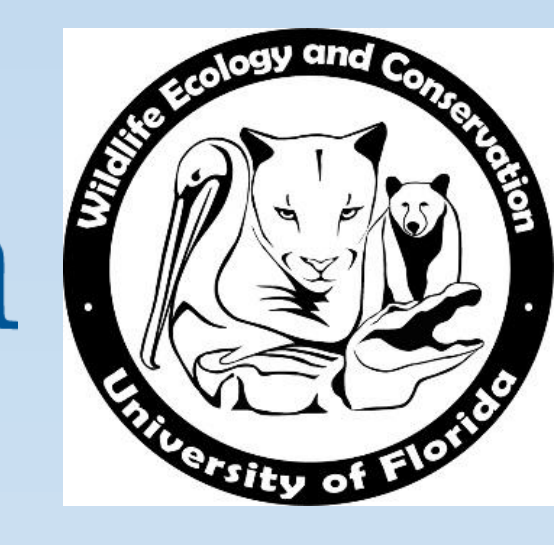

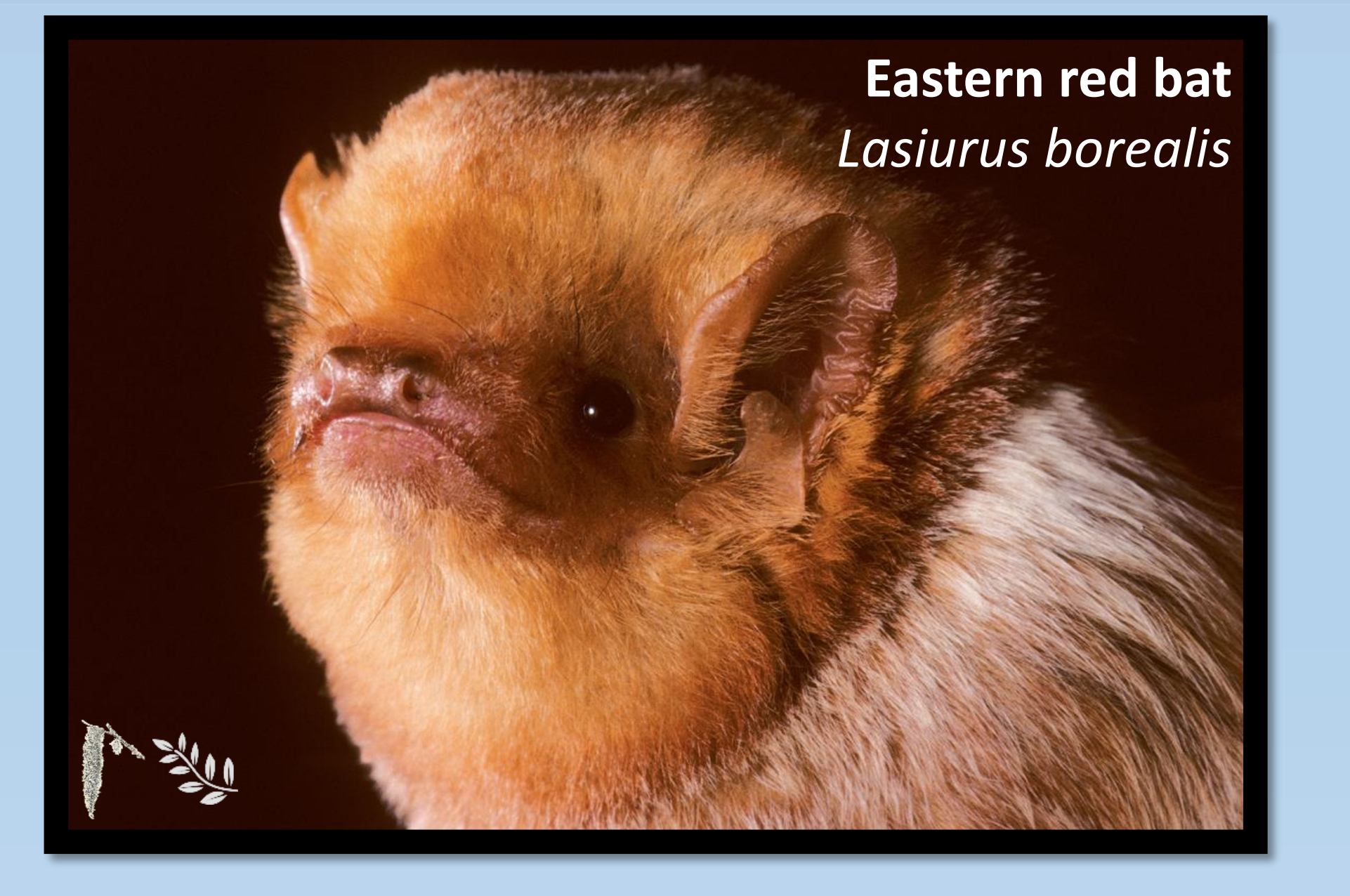

KEY TO COMMON ROOST STRUCTURES

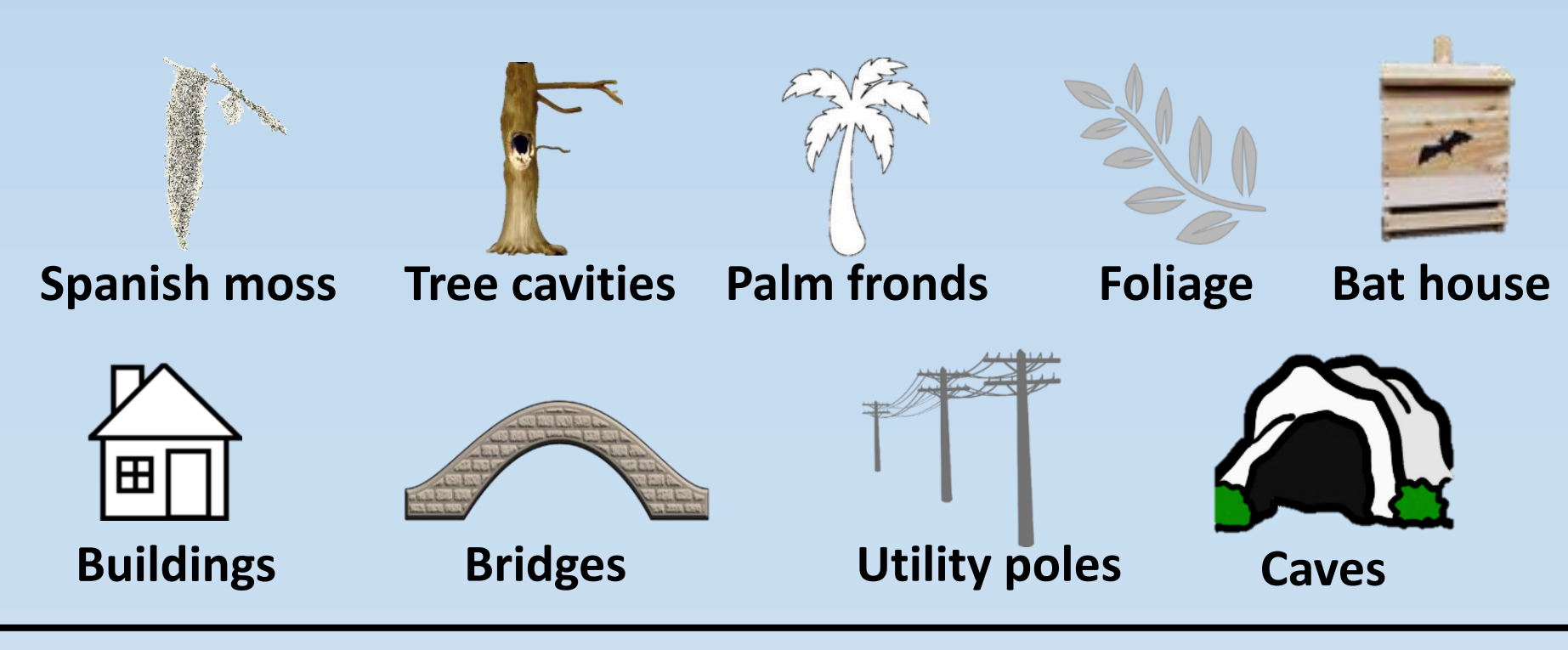

